\title{
PRODUÇÃO DE ETANOL ANIDRO VIA DESTILAÇÃO EXTRATIVA UTILIZANDO GLICEROL
}

\author{
H. A. JARDIM, L. F. MOURA e A. J. CRUZ \\ Universidade Federal de São Carlos, Departamento de Engenharia Química \\ E-mail para contato: herbertaires@gmail.com
}

\begin{abstract}
RESUMO - O etanol é um combustível renovável que teve sua produção incentivada no Brasil a partir do Programa Nacional do Álcool em 1975. Na safra 2012/13 foram produzidos 23,64 bilhões de litros, destes 9,85 bilhões em sua forma anidra. Nesta composição é utilizado como aditivo na gasolina ( $25 \%$ em volume), o que contribui para redução da dependência dos combustíveis fósseis, melhora do desempenho dos motores e diminuição na emissão de gases tóxicos. Neste trabalho foi empregado um aparelho de destilação em escala de bancada para avaliar a produção de etanol anidro por destilação extrativa com glicerol. O sistema foi simulado no simulador de processos Aspen Plus para três composições de etanol na corrente de alimentação $(25,35$ e $45 \% \mathrm{~m} / \mathrm{m})$. Em três simulações avaliou-se o sistema binário (etanol-água) e em outra empregou-se corrente de alimentação de glicerol. A coluna foi simulada em refluxo total com vazão de alimentação de etanol de $0,599 \mathrm{~L} / \mathrm{h}$ e de glicerol de $0,341 \mathrm{~L} / \mathrm{h}$. Na destilação binária a máxima pureza de etanol obtida no destilado foi de $94,1 \%$. Na destilação extrativa obteve-se pureza de 99,8\%. Nos experimentos realizados na destilação binária as concentrações de etanol no destilado foram de $90 \%$. No experimento com glicerol obteve-se no destilado uma pureza de etanol superior a 99\%. Para o sistema sem a presença de solvente, as eficiências de Murphree foram de 45, 30 e 35\%, respectivamente para 25, 35 e $45 \%$ de etanol na alimentação. Para o sistema com alimentação de glicerina a eficiência foi de $70 \%$.
\end{abstract}

\section{INTRODUÇÃO}

Existe uma grande preocupação em torno dos combustíveis fósseis, principalmente devido às incertezas sobre a sua disponibilidade no futuro e aos problemas ambientais causados pelo seu crescente uso. Com isso, a busca por fontes de energia renovável vêm ganhando destaque no cenário mundial. No Brasil, o etanol se apresenta como uma alternativa, sendo amplamente utilizado desde o final da década de setenta na forma hidratada como substituto à gasolina em motores adaptados para sua queima. Outro uso é na forma anidra, como aditivo à gasolina. Atualmente a gasolina consumida no Brasil possui $25 \%$ de etanol anidro (em volume) em sua composição (Portaria MAPA n ${ }^{\circ}$ 105, 28/02/2013). Quando o etanol é utilizado com a gasolina, ele atua como agente antidetonante, substituindo agentes tóxicos à base de chumbo que eram utilizados como aditivos da gasolina com esse propósito. $\mathrm{O}$ etanol também atua como oxigenante na mistura, promovendo uma melhor combustão, reduzindo-se assim a emissão de gases do efeito estufa (UNICA, 2007). A principal rota para a produção de etanol é a fermentativa, onde no Brasil é utilizada a cana-de-açúcar como matéria- 


\section{9 a 22 de outubro de 2014 \\ Florianópolis/SC}

prima. Após a fermentação, o etanol encontra-se diluído no vinho (6,0 a 10,0 $\left.{ }^{\circ} \mathrm{GL}\right)$ (MEIRELLES, 2006) e necessita ser concentrado e purificado. O vinho então é alimentado ao conjunto de colunas de destilação, onde ao fim desse processo obtém-se o etanol hidratado. Para ser adicionado como aditivo à gasolina é necessário sua desidratação. O álcool anidro deve possuir um teor mínimo de 99,3\% em massa de etanol (Portaria MAPA $n^{\circ}$ 678, 31/08/2011). A desidratação do etanol via destilação extrativa utilizando como solvente o mono etileno glicol é um método amplamente utilizado nas usinas. A escolha do solvente possui um grande impacto no processo e, portanto alguns parâmetros devem ser considerados como sua toxicidade, eficiência de separação e o consumo energético do sistema. É proposta nesse trabalho a utilização do glicerol como substituto ao mono etileno glicol (MEG). Essa substituição é motivada por diversos fatores como o crescimento da produção de biodiesel, que possui como subproduto o glicerol; a menor toxicidade do glicerol em relação ao MEG de acordo com HMSI (Hazardous Materials Identification System) (BDH, Glycerol, 2006; BDH, Ethylene Glycol, 2006); a maior capacidade em promover o aumento da volatilidade relativa da solução água-etanol apontado pelo trabalho experimental em equilibrio de fases de PLA-FRANCO et al., (2013); e o menor consumo energético do processo apontado pelo trabalho de simulação e otimização de UYAZÁN et al. (2006). Neste trabalho utilizou-se um aparelho de destilação de bancada para avaliar o processo de desidratação do etanol via destilação extrativa utilizando o glicerol como solvente após simulações no aplicativo Aspen Plus.

\section{MATERIAIS E MÉTODOS}

\subsection{Simulação}

Foi implementado no simulador de processos Aspen Plus sistema de destilação que representava o equipamento utilizado. Antes dos ensaios na coluna, simulações foram realizadas em quatro condições. A coluna foi simulada para operação em destilação binária, com alimentação de solução de etanol e água em três diferentes condições de alimentação. Uma simulação foi feita para o processo de destilação extrativa utilizando glicerol como solvente. As simulações da destilação binária foram feitas com o intuito comparativo, para se observar a influencia da presença do glicerol no processo. Os parâmetros utilizados foram baseados na faixa de operação dos equipamentos da coluna e foram ajustados em uma sequência de simulações. Para representar a coluna de destilação com o refervedor e o condensador foi utilizado o bloco RadFrac. Os banhos de aquecimento com a serpentina são representados pelo bloco Heater. Os fluxogramas da destilação binária e da destilação extrativa são apresentados na Figura 1. 


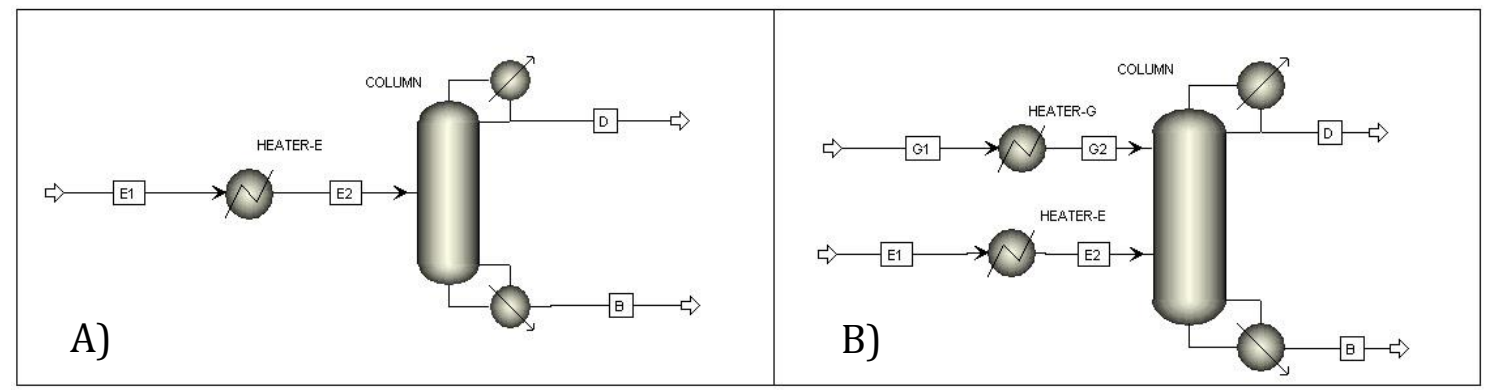

Figura 1. (A) Fluxograma da destilação binária e; (B) Fluxograma da destilação extrativa.

E1: Alimentação fria da solução de etanol

E2: Alimentação aquecida da solução de etanol

G1: Alimentação fria da glicerina

G2: Alimentação aquecida da glicerina

D: Destilado

B: Produto de fundo

HEATER-E: Trocador de calor da alimentação de etanol

HEATER-G: Trocador de calor da alimentação de glicerina

COLUMN: Coluna de destilação

Para as simulações do processo de destilação binária foram utilizadas as composições de 25,35 e 45 por cento em massa de etanol na alimentação e para a simulação do processo de destilação extrativa com glicerol foi utilizado uma alimentação com 35 por cento em massa de etanol. Para as quatro simulações foram utilizadas o modelo termodinâmico NRTL; corrente E1 com vazão de 0,599 $\mathrm{L} / \mathrm{h}$, temperatura de $25^{\circ} \mathrm{C}$ e pressão de 1 bar; temperatura da corrente $\mathrm{E} 2$ de $77,5^{\circ} \mathrm{C}$; Coluna com cálculo de equilíbro, 17 estágios, condensador total, razão de refluxo 100, potência do refervedor de $225 \mathrm{~W}$ e estágio da alimentação E2 no décimo prato contando a partir do condensador. Para o processo de destilação extrativa utilizou-se a corrente $\mathrm{G} 1 \mathrm{com}$ vazão de $0,341 \mathrm{~L} / \mathrm{h}$, temperatura de $25^{\circ} \mathrm{C}$, pressão de 1 bar, composição de $99,5 \%$ de glicerol e $0,5 \%$ de água; temperatura da corrente E2 de $77,5^{\circ} \mathrm{C}$ e estágio da alimentação E2 no segundo prato a partir do condensador.

\subsection{Equipamentos}

Para a realização dos experimentos foi empregado um aparelho de destilação em escala de bancada com 15 pratos perfurados. A fotografia do equipamento é apresentada na Figura 2 (A) e o esquema detalhado na Figura 2 (B). 


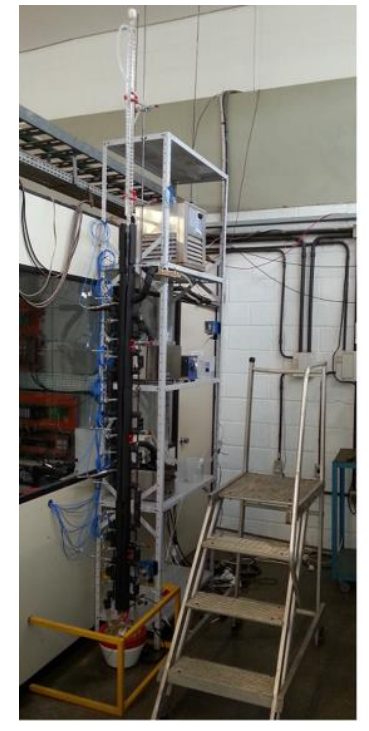

A)

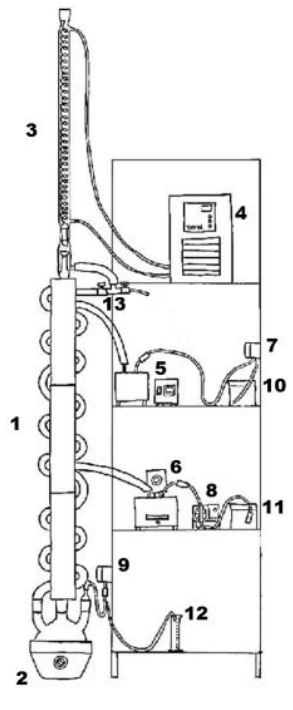

1. Coluna de destilação de vidro com 15 pratos perfurados e isolamento térmico;

2. Manta de aquecimento com balão de fundo redondo de 3 bocas (refervedor);

3. Condensador de vidro do tipo serpentina;

4. Banho termostatizado (resfriamento do condensador);

5. Banho de aquecimento com serpentina (alimentação de glicerina);

6. Banho de aquecimento com serpentina (alimentação de etanol);

7. Bomba peristáltica (alimentação de glicerina);

8. Bomba dosadora (alimentação de etanol);

9. Bomba peristáltica (retirada de produto de fundo);

10. Béquer com solução de glicerina;

11. Béquer com solução de etanol;

12. Proveta (retirada de produto de fundo);

13. Válvulas do destilado e refluxo

Figura 2. (A) Fotografia do equipamento de destilação e; (B) Diagrama esquemático do equipamento de destilação. (Fonte: Acervo Pessoal)

O sistema possui termopares no condensador, refervedor e nos pratos 1, 3, 6, 9 e 12 (numeração a partir do condensador). De acordo com o fabricante a precisão de cada termopar é de $0,5^{\circ} \mathrm{C}$. As soluções hidroalcoólicas foram preparadas empregando como reagente etanol absoluto PA (99,5\% v/v, Synth $\left.{ }^{\circledR}\right)$ nas diferentes diluições estabelecidas para cada experimento. No ensaio de destilação extrativa empregou-se na alimentação de solvente glicerina PA $(99,5 \% \mathrm{~m} / \mathrm{m}$ em glicerol e 0,5\% em massa de água, Synth®).

\subsection{Ensaios}

Foram realizados quatro ensaios referentes às simulações desenvolvidas. Os parâmetros de operação dos ensaios foram os mesmos das simulações. A manta de aquecimento e as bombas foram previamente calibradas. $\mathrm{O}$ procedimento para todos os experimentos foi idêntico. Inicialmente o balão do refervedor foi preenchido até a metade com a solução da alimentação. O sistema foi operado em refluxo total sem alimentação por uma hora para estabilizar a coluna. Depois iniciou-se a alimentação de solvente (para o processo de destilação extrativa) e de etanol na temperatura aproximada de $77,5^{\circ} \mathrm{C}$, mantendo o sistema em refluxo total. Esperou-se mais 30 minutos e iniciou-se a aquisição de temperatura, a coleta de produto de fundo e de destilado. As coletas foram feitas com um intervalo de 30 minutos cada. Foram realizadas cinco coletas para cada ensaio do processo de destilação binária e dez coletas para o processo de destilação extrativa. As amostras foram coletadas em frascos da marca Eppendorf de $2 \mathrm{ml}$. 


\section{9 a 22 de outubro de 2014 \\ Florianópolis/SC}

\subsection{Análises das amostras}

As amostras coletadas foram analisadas por refratometria. Foram preparadas quatro soluções padrão de 50 gramas cada com 5, 10, 15, 20 e 25\% em massa de etanol. Como reagente foi utilizado etanol absoluto PA (99,5\% v/v de etanol, Synth®) e água destilada. O etanol foi adicionado em um béquer de $100 \mathrm{ml}$, aferindo-se a massa com uma balança analítica. Depois completaram-se os 50 gramas da solução com água destilada. Os índices de refração das quatro soluções preparadas foram analisados em um refratômetro digital modelo Brix/RI-Check da Reichert® que possui precisão de 0,0002. Também foi analisado o índice de refração da água destilada pura. A partir desses resultados determinou-se uma equação linear (Equação 1) que relaciona a fração mássica de etanol pelo índice de refração para faixa de 0 à $25 \%$ de etanol. Todas as análises de refratometria foram realizadas na temperatura de $23,5^{\circ} \mathrm{C}$.

$$
x=14,853980 \cdot I R-19,789396
$$

onde x é a fração mássica de etanol e IR é o índice de refração.

O valor de $\mathrm{R}^{2}$ obtido foi de 0,9993 , o que confirma a linearidade dessa relação na faixa estabelecida. Para determinar o erro associado a essa medida foram preparados três padrões nas concentrações de 2,5, 12,5 e 22,5\% em massa de etanol. Essas amostras foram analisadas no refratômetro e as concentrações foram determinadas pela equação 1. Com isso foi possível determinar a média do erro entre o valor padrão e o valor calculado de cada amostra, além do desvio padrão. A média do erro foi de 0,36\% e o desvio padrão de 0,16. As amostras coletadas foram diluídas em um béquer com água destilada, medindo-se a massa inicial e final com a balança analítica. Foi analisado o índice de refração de cada amostra e com isso as concentrações das soluções diluídas foram obtidas aplicando-se a Equação 1. As concentrações reais foram determinadas multiplicando-se os valores das concentrações diluídas pelos fatores de diluição. Para as amostras de destilado do ensaio do processo de destilação extrativa as concentrações foram medidas por Cromatografia Líquida de Alta Eficiência para averiguar se houve uma contaminação de glicerol, o que invalidaria a análise por refratometria.

\section{RESULTADOS E DISCUSSÃO}

Na Tabela 1 são apresentados os resultados das frações mássicas de etanol obtidas no destilado das quatro simulações estudadas:

Tabela 1 - Resultados das frações mássicas de etanol obtidas no destilado das simulações

\begin{tabular}{|c|c|c|c|}
\hline binário $25 \%(\mathrm{~m} / \mathrm{m})$ & binário 35\% $(\mathrm{m} / \mathrm{m})$ & binário $45 \%(\mathrm{~m} / \mathrm{m})$ & destilação extrativa $(\mathrm{m} / \mathrm{m})$ \\
\hline 0,9402 & 0,9406 & 0,9410 & 0,9981 \\
\hline
\end{tabular}

Observa-se que as concentrações de etanol para os processos binários são muito próximas e seus 
valores encontram-se abaixo do ponto de azeotropia que é de aproximadamente 95,6\% em massa de etanol. Com a adição da corrente de solvente nota-se um grande aumento na pureza de etanol. $\mathrm{O}$ glicerol permitiu a quebra do azeótropo e a obtenção de etanol anidro com uma pureza além da estabelecida pela ANP de 99,3\%.

Na tabela 2 são apresentados os resultados das frações mássicas de etanol obtidas no destilado dos quatro ensaios estudados. Como nas análises realizadas por CLAE não se detectou traços de glicerol no destilado do processo de destilação extrativa foi possível fazer a análise por refratometria.

Tabela 2 - Resultados das frações mássicas de etanol obtidas no destilado dos ensaios

\begin{tabular}{|c|c|c|c|c|}
\hline Amostras & $\begin{array}{c}\text { binário 25\% } \\
(\mathrm{m} / \mathrm{m})\end{array}$ & $\begin{array}{c}\text { binário 35\% } \\
(\mathrm{m} / \mathrm{m})\end{array}$ & $\begin{array}{c}\text { binário 45\% } \\
(\mathrm{m} / \mathrm{m})\end{array}$ & destilação extrativa $(\mathrm{m} / \mathrm{m})$ \\
\hline 1 & 0,902 & 0,895 & 0,849 & 0,977 \\
\hline 2 & 0,921 & 0,882 & 0,868 & - \\
\hline 3 & 0,913 & 0,898 & 0,891 & 0,987 \\
\hline 4 & 0,911 & 0,889 & 0,908 & 0,994 \\
\hline 5 & 0,928 & 0,881 & 0,939 & 0,995 \\
\hline 6 & - & - & - & 0,985 \\
\hline 7 & - & - & - & 0,998 \\
\hline 8 & - & - & - & 0,997 \\
\hline 9 & - & - & - & 0,995 \\
\hline 10 & - & - & - & 0,985 \\
\hline
\end{tabular}

Os valores experimentais de pureza do etanol no destilado foram menores em comparação com as simulações, pois os estágios da coluna não estão em equilíbrio. Contudo é possível observar que a presença do glicerol no ensaio do processo de destilação extrativa promoveu a quebra do azeótropo além de permitir obter a pureza exigida pela ANP para o álcool anidro em certos pontos do processo, como é possível observar pelas amostras 4, 5, 7, 8 e 9. Com o erro experimental de 0,36\% é possível que as amostras 4, 5 e 9 não tenham atingido o valor mínimo de 99,3\% em massa de etanol.

Para avaliar a eficiência dos processos em regime estacionário, realizou-se uma média com os três últimos valores de concentração de etanol no destilado para os processos de destilação binária e uma média com os cinco últimos valores do processo de destilação extrativa. Novas simulações foram realizadas para determinar o valor de eficiência de Murphree que resulta em um destilado com mesmo valor das médias das concentrações dos ensaios. Obtiveram-se os valores de 45, 30 e 35\% de eficiência para os processos de destilação binária com alimentações de 25, 35 e $45 \%$ em etanol respectivamente e uma eficiência de $70 \%$ para o processo de destilação extrativa. Na Figura 3 é apresentado o perfil de temperatura dos estágios para os ensaios, as simulações com eficiência de $100 \%$ e com o valor de eficiência determinada. Para os ensaios realizou-se uma média de temperatura para a última metade de cada experimento para representar o processo em regime permanente. 

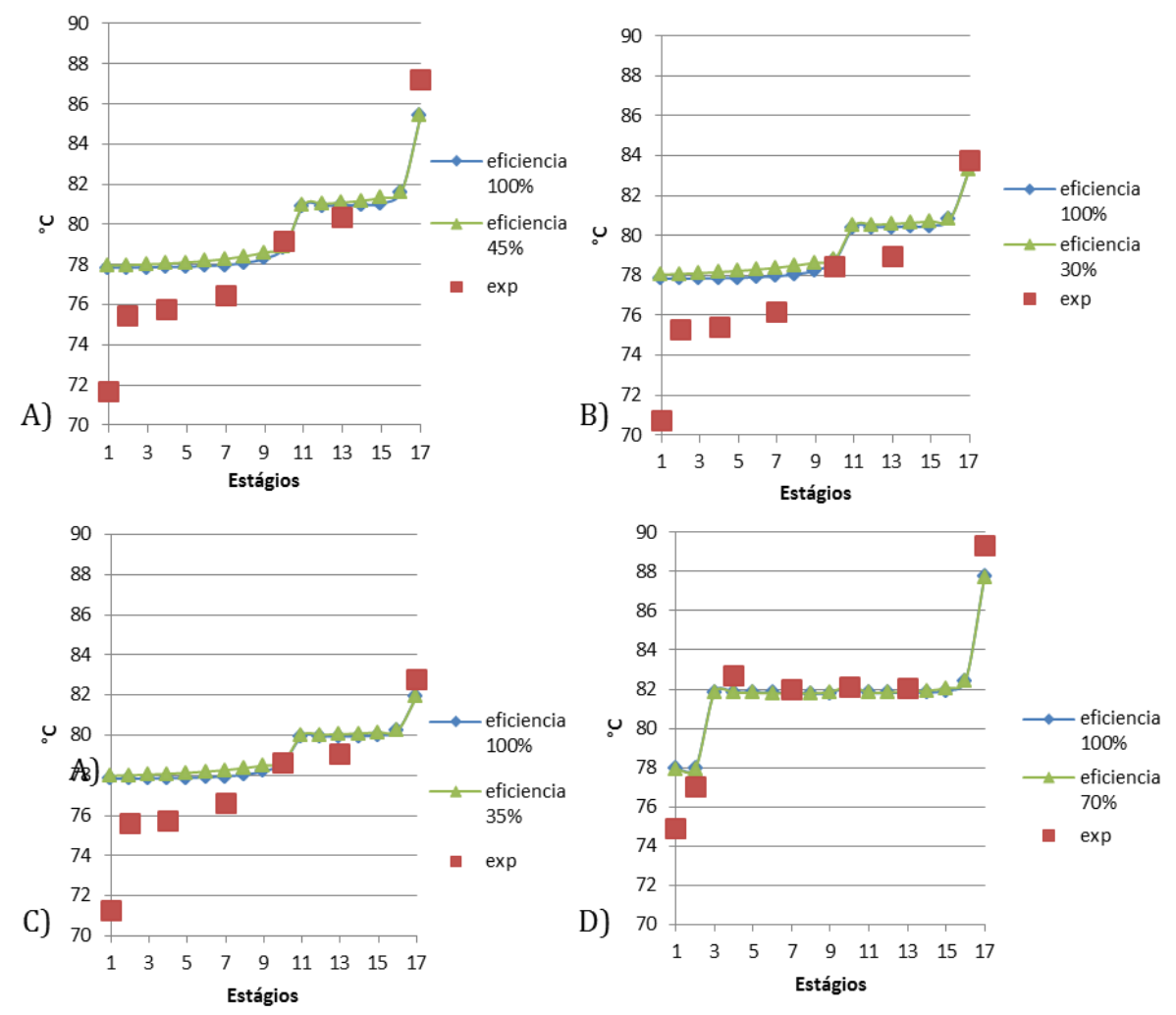

Figura 3. (A) Perfil de temperatura do processo de destilação binária com alimentação de $25 \%$ de etanol; (B) Perfil de temperatura do processo de destilação binária com alimentação de 35\% de etanol; (C) Perfil de temperatura do processo de destilação binária com alimentação de $45 \%$ de etanol e; (D) Perfil de temperatura do processo de destilação extrativa.

Observa-se que o perfil de temperatura das simulações com eficiência de $100 \%$ e as simulações com eficiência determinada possuem um perfil de temperatura semelhante. Isso ocorre, pois pequenas variações de temperatura representam grandes variações da composição. Os perfis de temperatura dos ensaios divergiram dos perfis das simulações nos estágios próximos ao condensador, pois o líquido do refluxo encontrava-se sub-resfriado, contribuindo com a perda de eficiência do processo.

\section{CONCLUSÕES}

O uso do glicerol como solvente no processo de destilação extrativa mostrou-se satisfatório. Enquanto a destilação binária atingiu no destilado concentrações da ordem de $90 \%$, a destilação extrativa com glicerol atingiu a pureza de etanol anidro. As vantagens do glicerol associadas a sua baixa toxicidade, alta eficiência de separação e a sua crescente disponibilidade em função da 
produção de biodiesel o colocam como um potencial candidato a substituir o mono etileno glicol no processo de desidratação de etanol via destilação extrativa.

\section{AGRADECIMENTOS} trabalho.

Os autores agradecem a CAPES e ao CNPq pelo apoio financeiro para realização deste

\section{REFERÊNCIAS BIBLIOGRÁFICAS}

ANP. PORTARIA MAPA No 678, DE 31.8.2011 - DOU 1.9.2011. Disponível em www.anp.gov.br. Acessado em Novembro/2012.

ANP. PORTARIA MAPA No 105, DE 28.2.2013 - DOU 1.3.2013. Disponível em www.anp.gov.br. Acessado em Maio/2013.

BDH. Material Safety Data Sheet: Ethylene Glycol. Middle East, p.1-9, janeiro 2006.

BDH. Material Safety Data Sheet: Glycerol. Middle East, p.1-8, janeiro 2006.

MEIRELlES, A. J. A. Expansão da Produção de Bioetanol e Melhoria Tecnológica da Destilação Alcoólica. Preparado para o Workshop "Produção de Etanol” em EEL/USP. FEA/UNICAMP, Campinas, SP. 2006.

PLA-FRANCO, J. et al.. Phase equilibria for the ternary systems ethanol, water + ethylene glycol or + glycerol at $101.3 \mathrm{kPa}$. Elsevier, p.54-60, janeiro 2013.

UYAZÁN, A. M. et al. Produccíon de alcohol carburante por destilación extractiva: Simulación Del proceso com glicerol. Revista Inginiría e Investigación, Bogotá, p.45-50, abril 2006. 